\title{
Espécies novas de Ischnoptera (Blattellidae, Blattellinae) do Brasil
}

\author{
Edivar H. de Oliveira \& Sonia Maria Lopes
}

Departamento de Entomologia, Museu Nacional, Universidade Federal do Rio de Janeiro, Quinta da Boa Vista, São Cristóvão, 20940-040 Rio de Janeiro, Brasil. (sonialfraga@gmail.com)

\begin{abstract}
New species of Ischnoptera (Blattellidae, Blattellinae) from Brazil. Two new species of Ischnoptera Burmeister, 1838 from state of Rio de Janeiro, Brazil are described. The genitalia of males (median sclerite and right and left phallomeres) is illustrated. Both species were collected in the municipality of Iguaba Grande, formerly an area with restinga vegetation, which is now being devastated.
\end{abstract}

KEYWORDS. Rio de Janeiro, Blattaria, taxonomy.

RESUMO. Duas espécies novas de Ischnoptera Burmeister, 1838 do estado do Rio de Janeiro, Brasil são descritas. São apresentadas ilustrações da genitália dos machos (esclerito mediano, e falômeros esquerdo e direito). Ambas as espécies foram coletadas no município de Iguaba Grande, em uma área com vegetação de restinga, que atualmente vem sendo devastada.

PALAVRAS-CHAVE. Rio de Janeiro, Blattaria, taxonomia.

Ischnoptera foi descrito por BURMEISTER (1838) com base em Ischnoptera morio, espécie-tipo posteriormente designada por KIRBY (1904).

$\mathrm{O}$ gênero apresenta grande diversidade tanto em relação à quantidade de espécies como na configuração das estruturas genitais, o que faz com que seja dividido em grupos (HeBARD, 1917; Roth, 2001, 2002). Na literatura estão registradas 91 espécies distribuídas em países da América do Sul, América Central e Antilhas (BECCALONI, 2007). No Brasil são conhecidas cerca de 40 espécies, das quais 29 foram assinaladas até o momento em países da América do Sul (BECCALONI, 2007).

São espécies que geralmente apresentam coloração castanho-clara, brilhante; cabeça castanho-escura; olhos negros. Tégmina com tronco inicial de todas as nervuras castanho-escuro sendo desenvolvidas, ultrapassando em comprimento o ápice dos cercos; campo marginal curto e estreito; campo escapular estreito e oblíquo; campo discoidal amplo e longitudinal; campo anal longo e alargado. Asas desenvolvidas, triângulo apical pouco desenvolvido; campo costal com ápice dos ramos da nervura radial pouco dilatado; campo anal dobrado em leque. Pernas com intensa tomentosidade dourada desenvolvidas e espinhosas. Fêmur anterior tipo B, na face ântero-ventral, com quatro espinhos robustos seguidos por uma série cerrada de espinhos pequenos até o ápice e três espinhos grandes apicais (RоTH, 2001); face póstero-ventral com dois espinhos robustos, espaçados e mais um apical. Fêmures médio e posterior com a disposição dos espinhos semelhante em ambas as faces ventrais, com quatro espinhos robustos e espaçados, e mais um apical. Presença de espinho genicular nos dois últimos fêmures descritos.

Neste trabalho assinala-se, pela primeira vez, a ocorrência do gênero para o município de Iguaba Grande no estado do Rio de Janeiro, e acrescentam-se mais duas espécies novas coletadas nesse município.

\section{MATERIAL E MÉTODOS}

O material foi coletado no município de Iguaba
Grande, cidade situada na Região dos Lagos, em uma área de $54 \mathrm{~km}^{2}$ a uma altitude de $18 \mathrm{~m}$, localizada às margens da lagoa de Araruama, distante $123 \mathrm{~km}$ do Rio de Janeiro (22 $50^{\prime} 21^{\prime \prime}$ 'S, $\left.42^{\circ} 13^{\prime} 44^{\prime \prime} \mathrm{W}\right)$. Na época em que o material foi coletado a área apresentava vegetação de restinga que atualmente foi devastada pela invasão imobiliária.

O material foi coletado em uma área denominada como chácara das Rosas, com auxílio de armadilha luminosa e levado ao laboratório mergulhado em álcool etílico a 70\%. Em laboratório, a observação das placas e peças genitais dos exemplares seguiu LOPES \& OLIVEIRA (2000) e a designação das peças genitais e a classificação taxonômica foram baseadas nos conceitos propostos por Rотн (2003). Medidas são expressas em milímetros.

Após análise, as placas e peças genitais foram guardadas em microtubo contendo glicerina e devidamente acondicionadas junto ao exemplar respectivo, montado em alfinete entomológico na coleção, técnica desenvolvida por GURNEY et al. (1964). O material examinado encontra-se depositado na coleção entomológica do Museu Nacional do Rio de Janeiro (MNRJ).

\section{Ischnoptera iguabense sp. nov. (Figs 1-8)}

Holótipo ơ. Coloração nos palpos bucais amarelada com tomentosidade dourada, antenas castanhas; manchas ocelares castanho-alaranjadas. Pronoto com disco central castanho-escuro, com abas laterais e faixa anterior castanho-amareladas claras.

Cabeça triangular (Fig. 1); vértice exposto; olhos desenvolvidos e posicionados lateralmente; espaço interocular amplo. Ocelos grandes e defletidos em relação à fronte (Fig. 1); palpos bucais desenvolvidos e tomentosos.

Tórax com pronoto sub-trapezoidal, convexo, com abas laterais com entorno arredondado, ápice e base retos (Fig. 2).

Abdome com modificação tergal (Fig. 3) típica do gênero, presente, medianamente, no sétimo e oitavo 
segmentos, caracterizada por duas projeções em forma de duas barras paralelas cujas áreas pré-apicais apresentam três espinhos longos, voltados para a margem interna do segmento, projeções essas que se sobrepõem parcialmente ao oitavo segmento. Placa supra-anal (Fig. 5) não esclerotinizada e projetada entre os cercos e arredondada, levemente assimétrica apresentando reentrância de um dos lados, parapróctos esclerotinizados e distintos com cílios nas bases; cercos desenvolvidos e cerdosos. Placa subgenital (Fig. 8) assimétrica com cerdas pequenas, concentradas mais ao centro na superfície externa e no entorno apical e lateral da placa, estilos assimétricos inseridos em uma projeção mediana apical da placa, cerdosos e de tamanhos diferentes. Esclerito mediano longo com o ápice diferenciado em forma de uma garra (Fig. 6). Falômero esquerdo em forma de gancho medianamente afilado e apicalmente mais desenvolvido (Fig. 4). Falômero direito (Fig. 7) basalmente afilado e alongado, com três escleritos: um com os braços assimétricos, um deles mais largo e o outro afilado apresentando, medianamente, duas estruturas esclerotinizadas.

Medidas. Holótipo $0^{\top}$. Comprimento total 13,0. Pronoto: comprimento 2,5; largura 3,5. Tégmina: comprimento 12,0; largura 3,5. Parátipo . Comprimento total 14,0. Pronoto: comprimento 3,0; largura 4,0. Tégmina: comprimento 12,0; largura 3,5.

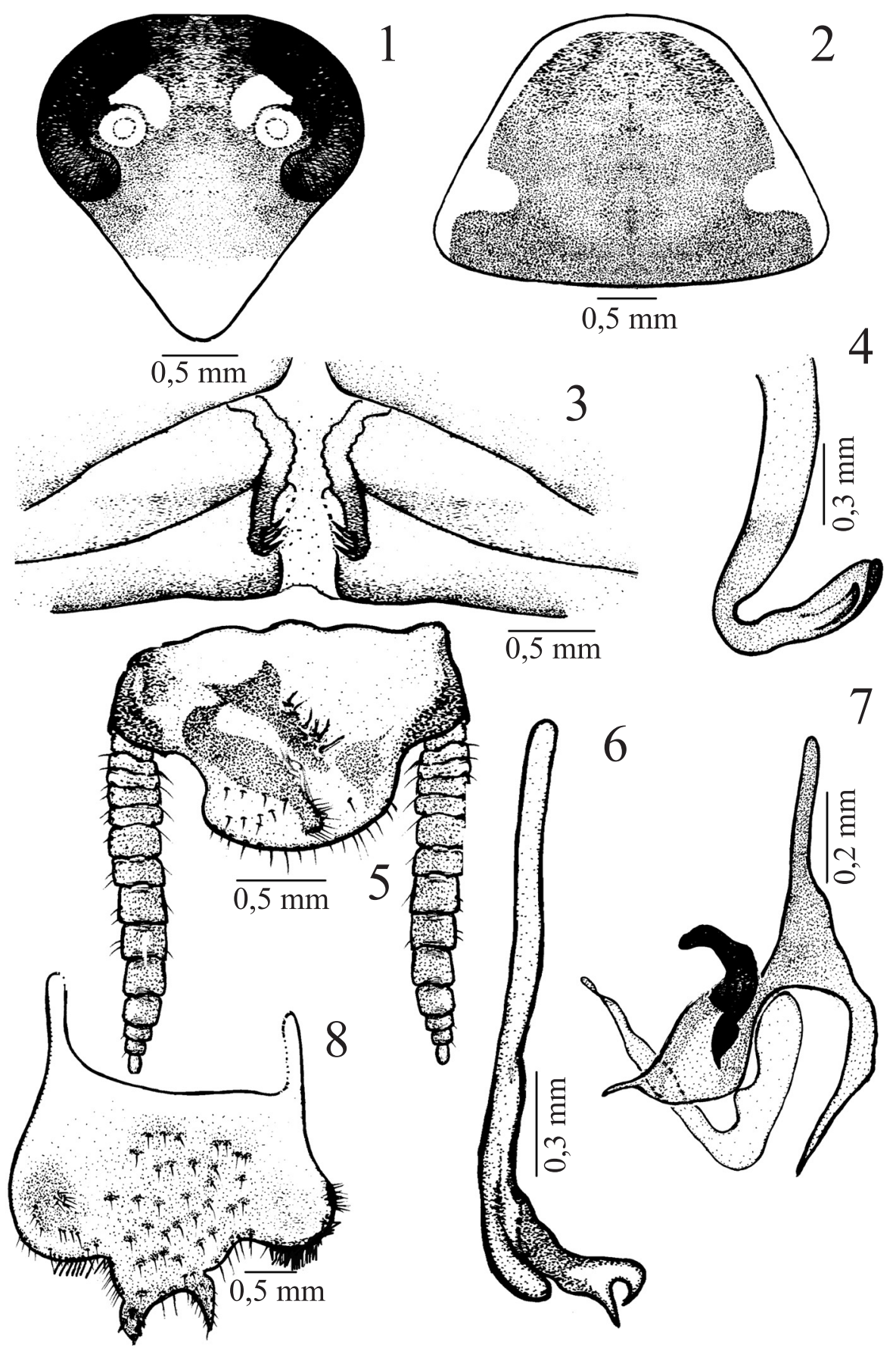

Figuras 1-8. Ischnoptera iguabense sp. nov., holótipo macho: 1, cabeça, vista ventral; 2, pronoto, vista dorsal; 3, modificação tergal; 4, falômero esquerdo, vista dorsal; 5, placa supra-anal, vista dorsal; 6, esclerito mediano; 7, falômero direito, vista dorsal; 8, placa subgenital, vista ventral. 
Material-tipo. Holótipo $\sigma^{\star}$, BRASIL, Rio de Janeiro: Iguaba Grande, IX.1996, E. H. Oliveira col. Parátipos, 2Q, mesma localidade do holótipo, IV.1997, em armadilha luminosa (MNRJ).

Etimologia. O nome da espécie refere-se ao município onde foi coletado o material.

Diagnose. Espécie pertencente ao grupo rufa (RoTH, 2002) pela coloração do exemplar que não é negra e pelas configurações das placas subgenital, supra-anal que não é trapezóide e sim arredondada e pronunciada entre os cercos e não é esclerotinizada e pela tégmina da fêmea totalmente desenvolvida. Presença de pequeno lobo lateral no esclerito mediano o que a aproxima das espécies pertencentes ao grupo deropeltiformes. A formação em garra do ápice do esclerito mediano e das demais estruturas a distingue de todas as demais espécies do gênero.

\section{Ischnoptera oliveirai sp. nov.}

(Figs 9-16)

Holótipo ơ Coloração nas antenas com tomentosidade dourada; peças bucais com extremidade do artículo apical mais escura. Pronoto castanho-claro, com duas manchas castanho-escuras simétricas e paralelas.
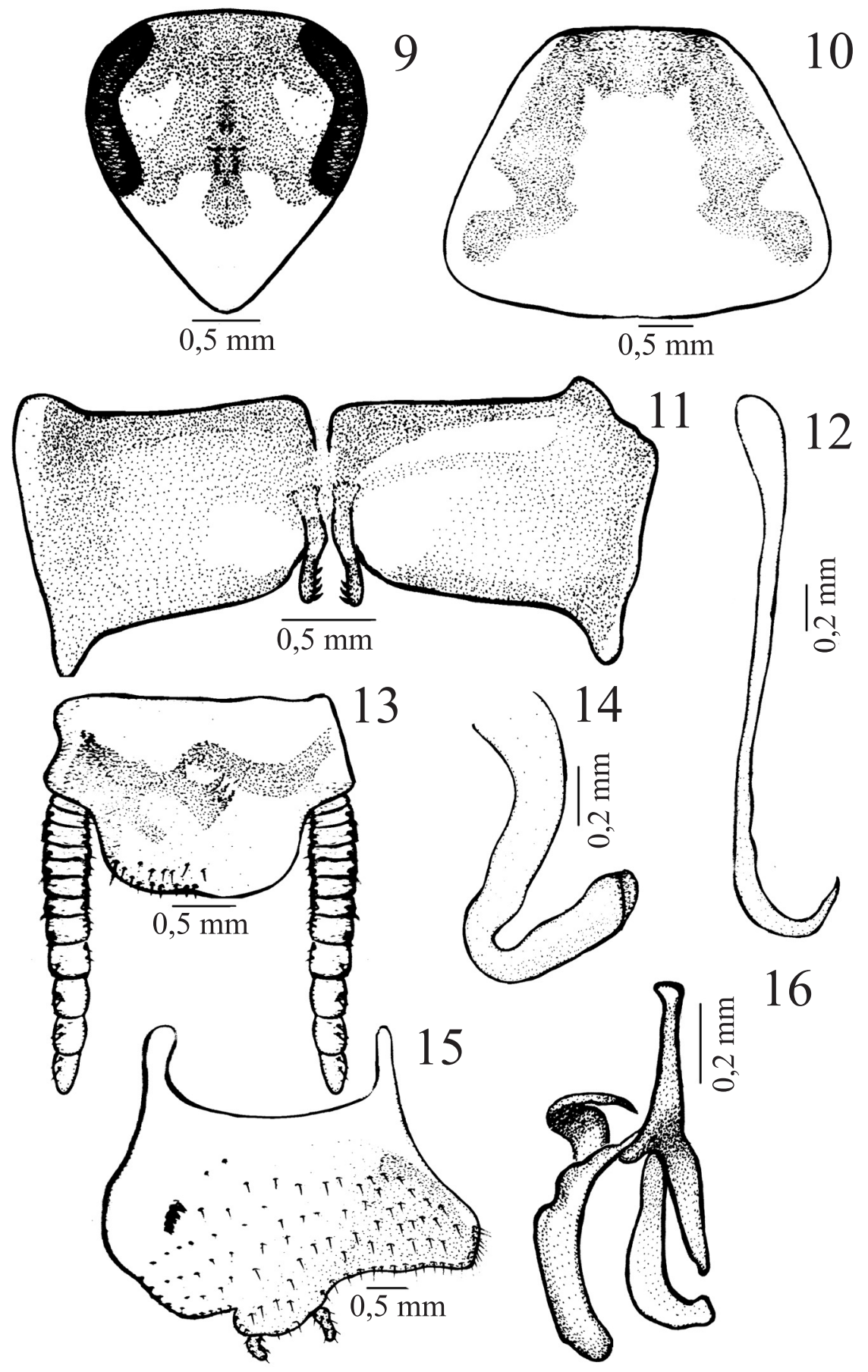

Figuras 9-16. Ischnoptera oliveirai sp. nov., holótipo macho: 9, cabeça, vista ventral; 10, pronoto, vista dorsal; 11, modificação tergal; 12, esclerito mediano, vista dorsal; 13, placa supra-anal, vista dorsal; 14, falômero esquerdo, vista dorsal; 15, placa subgenital, vista ventral; 16, falômero direito, vista dorsal. 
Cabeça subtriangular (Fig. 9), vértice encoberto pelo pronoto; espaço interocular amplo medindo cerca de dois terços da área que separa as bases das inserções antenais. Antenas longas, ultrapassando em comprimento o ápice dos cercos; manchas ocelares presentes, fronte projetada e saliente; palpos maxilares desenvolvidos.

Tórax apresentando pronoto trapezoidal, com abas laterais e entorno arredondado (Fig. 10).

Abdome. Modificação tergal (Fig. 11) típica do gênero, presente medianamente nos sétimo e oitavo segmentos, caracterizada por duas projeções em forma de barras paralelas, cuja área pré-apical apresenta três ou quatro espinhos curtos, voltados para a margem interna do segmento, projeções essas que se sobrepõem parcialmente ao oitavo segmento. Placa supra-anal (Fig. 13) simétrica, sem esclerotinização evidenciada e projetada entre os cercos e de ápice arredondado, cercos desenvolvidos e cerdosos, parapróctos assimétricos e diferenciados em forma e tamanho no interior da placa, apicalmente, com espinhos. Placa subgenital (Fig. 15) assimétrica e cerdosa, projetada em um dos lados, estilos inseridos em uma projeção mediana apical da placa, pequenos e próximos e com muitas cerdas. Esclerito mediano (Fig. 12) desenvolvido, afilado e recurvado no ápice em forma de um anzol. Falômero esquerdo (Fig. 14) em forma de gancho com reentrância mediana. Falômero direito (Fig. 16) com três escleritos desenvolvidos, um com os braços assimétricos de tamanho diferenciado, e outros dois como estruturas medianas esclerotinizadas.

Medidas. Holótipo o'. Comprimento total 15,0. Pronoto: comprimento 3,0; largura 3,5. Tégmina: comprimento 13,0; largura 3,5.

Material-tipo. Holótipo on, BRASIL, Rio de Janeiro: Iguaba Grande, II.1996, E. C. Oliveira \& E. H. Oliveira col. (MNRJ).

Etimologia. O nome da espécie é em homenagem ao coletor Edgar Corrêa de Oliveira.
Diagnose. Espécie que integra o grupo bilunata (Rотн, 2002) por apresentar pronoto claro com manchas escuras. A configuração da placa subgenital e do esclerito mediano afilado e recurvado no ápice em forma de um anzol aproximam das espécies do grupo bilunata. Os demais caracteres já citados na descrição diferenciam-na das demais espécies do gênero.

Agradecimentos. Ao $\mathrm{CNPq}$ pela bolsa de pesquisa concedida a SML.

\section{REFERÊNCIAS BIBLIOGRÁFICAS}

Beccaloni, G. W. 2007. Blattodea Species File Online (version 1.2/3.5). Disponível em: 〈http://Blattodea.speciesfile.org〉. Acesso em: 29.12.2010.

Burmeister, H. 1838. Blattina. In: Handbuch der Entomologie. Berlin, I.C.F. Enslin. v.2, pt. 2, p.469-517.

Gurney, A. B.; Kramer, J. P. \& Steyskal, G. C. 1964. Some techniques for the preparation, study and storage in microvials of insect genitalia. Annals of the Entomological Society of America 57(2):240-242.

Hebard, M. 1917. The Blattidae of North America, north of the Mexican boundary. Memorial American Entomological Society 2:1-284.

KiRBY, W. F. 1904. A synonymic catalogue of Orthoptera Euplexoptera, Cursoria et Goessinia (Forficulidae, Hemimeridae, Blattidae, Mantidae, Phasmidae). London, British Museum. v.1, 501p.

Lopes, S. M. \& Oliveira, E. H. 2000. Espécie nova de Eublaberus Hebard, 1919 do estado de Goiás, Brasil e notas sobre E. marajoara Rocha e Silva-Albuquerque, 1972 (Blaberidae, Blaberinae). Boletim do Museu Nacional, Nova Série, Zoologia, 433:1-5.

Rотн, L. M. 2001. The genus Ischnoptera Burmeister. I. The darlingtoni-species-group, with seven new species (Blattaria: Blattellidae, Blattellinae). Transactions of the American Entomological Society 127(4):519-541

2002. The genus Ischnoptera Burmeister. II. Species from the United States (Blattellidae, Blattellinae). Transactions American of the Entomological Society 128:345-360. 2003. Systematics and phylogeny of cockroaches (Dictyoptera: Blattaria). Oriental Insects 37:1-186. 